\title{
Impact of shear strength parameters on slope stability
}

\author{
Slávka Harabinová ${ }^{1, *}$, Eva Panulinová ${ }^{1}$ \\ ${ }^{1}$ TU Kosice, Faculty of Civil Engineering, Vysokoskolska 4, 04200 Kosice, Slovakia
}

\begin{abstract}
Analysis and assessment of the slopes stability are an important in geotechnical engineering for all the times. The paper deals with the assessment of slope stability in fine-grained soils. The influence of change in shear strength parameters on the factor of safety has been studied. The factor of safety can be correctly obtained only if the critical failure surface of the slope is accurately identified and shear strength parameters are correctly. To investigate effect of soil strength parameters on the factor of safety, different values of shear strength parameters: cohesion $(c)$, internal friction angle $(\phi)$, were chosen. The calculation and assessment of slope stability was made using methods which assume a circular shape of the slip surface (Bishop and Petterson method) and methods that consider the polygonal shape of the slip surface (Spencer and Janbu method). We analyzed the impact of shear strength parameters of the resulting factor of slope stability of fine grained soil. The results of the study showed that the factor of safety of the slope changes with varying cohesion $c$ and internal friction angle $\phi$.
\end{abstract}

\section{Introduction}

Analysis and assessment of the slopes stability are an important in geotechnical engineering for all the times. Climatic factors combined with the erosion activity water courses and groundwater are major causes of slope deformations. The intensity and frequency of rainfall, frequent flood events are taking place in our area are also associated with rapid erosion processes, which consequently may lead to landslides of soil. Slopes saturated with water have become prone to landslide. Different values of shear strength parameters are caused floods.

The first and foremost requirement for the analysis and design of slope is to guarantee their safety and reliability during their service life. The factor of safety can be correctly obtained only if the critical failure surface of the slope is accurately identified and shear strength parameters are correctly. Geologists determine recommended dispersion of values, which may cause inaccuracies in calculation and assessment of slope stability. Situation in subsoil may also complicate occurrence of extreme loads, for example by changing soil consistency in event of a sudden increase or decrease in degree of water saturation. To investigate effect of soil strength parameters on the factor of safety, different values of

\footnotetext{
* Corresponding author: slavka.harabinova@tuke.sk
} 
shear strength parameters: cohesion $(c)$, internal friction angle $(\phi)$, were chosen. We analyzed the impact of shear strength parameters of the resulting factor of slope stability of fine grained soil.

In analyzing the overall stability of the ground, of soil or rock, all relevant modes of failure shall be taken into account.

The overall stability of slopes shall be verified in ultimate limit states (GEO and STR) [2]. When choosing a calculation method, should be considered: soil layering, occurrence and inclination of discontinuities, seepage and pore-water pressure distribution, short- and long-term stability, type of failure (circular or non-circular surface; toppling; flow), use of numerical methods.

\section{Methods used for slope stability analysis}

Currently are several methods for analyzing the stability of slopes, such as Petterson, Bishop, Janbu, Morgenstern-Price, Spencer or Sarma methods.

Most frequently, it is assumed in the methods that failure occurs along a particular slip surface. The shape of slip surface depends mainly on the physical and mechanical properties of soils or their arrangement in the profile.

It is possible to model the slip surface in two different manners: either as a circular surface or a polygonal one. The calculation and assessment of slope stability was made using methods which assume a circular shape of the slip surface (Bishop and Petterson method) and methods that consider the polygonal shape of the slip surface (Spencer and Janbu method) $[1,3,4,5]$.

Petterson Method is the oldest and simplest method of analyzing slope stability. It is the method of slices not considering the action of neighbouring elements. The sliding mass above a circular slip surface is divided into a number of vertical slices. The forces acting on each slice are obtained, given by their self-weight.

Bishop Method is a modified and extended version of Petterson Method. Horizontal actions of neighbouring slices are incorporate too into the calculation. Forces acting on individual elements for Bishop Method are displayed in the following figure (Fig.1).

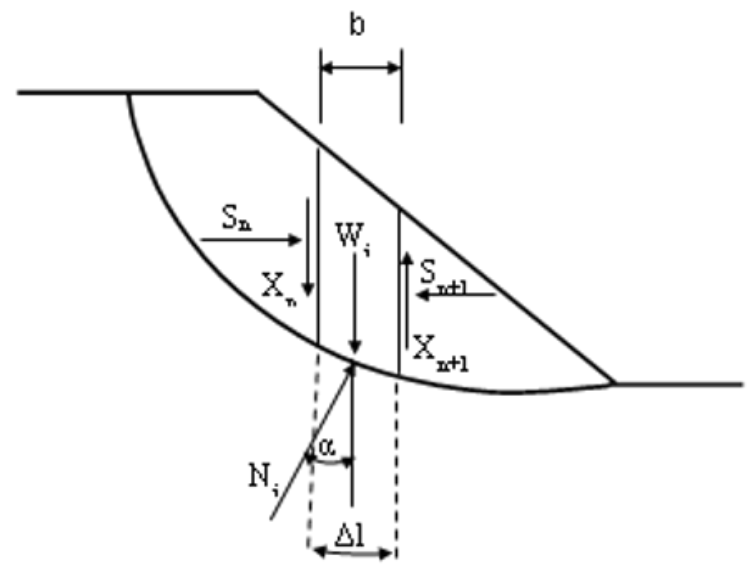

Fig. 1. Bishop Method - acting forces.

The Spencer method and the Janbu Method are a general methods developed on the basis of limit equilibrium. They require satisfying equilibrium of forces and moments acting on individual blocks, which are created by dividing the soil above the slip surface. Forces acting on individual blocks are displayed in the Figure 2. 


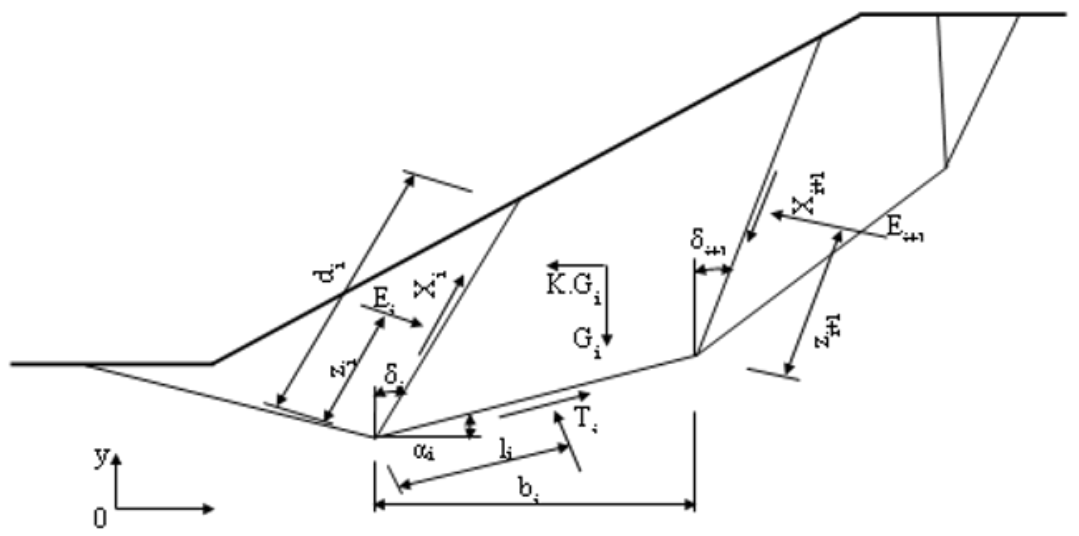

Fig. 2. Spencer Method - acting forces.

Slope stability analyses of taking into mechanical properties of soils were performed. Factors of safety of the slopes were determined employing Bishop, Petterson, Sarma and Janbu methods. The location of the slip surface was optimized by means of the GEO 5 program [5] and by this optimization, the most unfavourable factor of safety of the slope was determined.

\section{Numerical analysis}

Our experimental study focused on the city Košice, its metropolis city of Eastern Slovakia. We analyzed the impact of shear strength parameters of the resulting factor of slope stability of fine grained soil. The calculation and assessment of slope stability have been analyzed on fine soils - group F6.

\subsection{Input parameters}

The geological structure of Košice is predominantly composed of quaternary sediments (namely sediments of the Hornad River). The quaternary sediments are represented principally by gravel and gravel with silt or clay. On the surface, gravel sediments are covered with silts and clays of low plasticity. Their consistency is mostly soft to stiff.

Different values of cohesion $c=(8-16) \mathrm{kPa}$ and of frictional angle $\phi=(17-21){ }^{\circ}$ in calculation of slope stability was used (Table 1). The factor of safety was calculated for a 4 $\mathrm{m}$ high of slope.

Table 1: Geotechnical parameters of soil.

\begin{tabular}{|l|c|}
\hline \multicolumn{1}{|c|}{ Geotechnical parameters of soil } & $\begin{array}{c}\text { Group F6 } \\
\text { (CL, CI) }\end{array}$ \\
\hline Poisson's ratio $v(-)$ & 0.40 \\
\hline Unit weight $\gamma\left(\mathrm{kN} / \mathrm{m}^{3}\right)$ & 21.0 \\
\hline Effective stress parameter - cohesion $c(\mathrm{kPa})$ & $8-16$ \\
\hline Effective stress parameter - angle of friction $\phi\left(^{\circ}\right)$ & $17-21$ \\
\hline
\end{tabular}




\subsection{Results and discussion}

A factor of safety is defined as the ratio of the forces resisting movement to those driving movement, i.e. the ratio between the active and passive forces. In general, if the factor of safety of a slope is within the interval between 0 and 1.0, the slope is unstable. The value over 1.0 indicates that the slope is considered stable.

Calculation and assessment of slope stability was carried out by using program "Slope stability", which is a sub-program of GEO 5 by company FINE Ltd [5]. The impact of shear strength parameters of the resulting factor of slope stability of fine grained soil is shown in the next figures (Fig. 3 and Fig. 4).

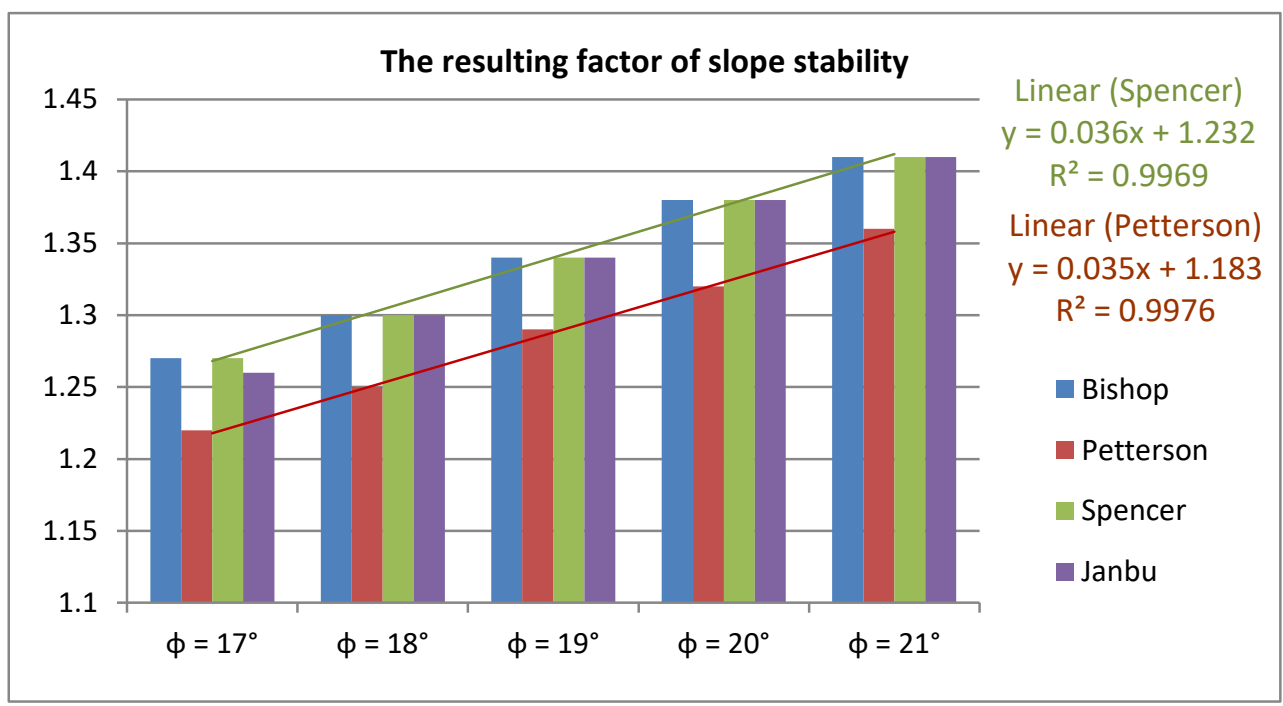

Fig. 3. The resulting factor of safety for $\mathrm{c}=8 \mathrm{kPa}$ and $\varphi=(17-21){ }^{\circ}$

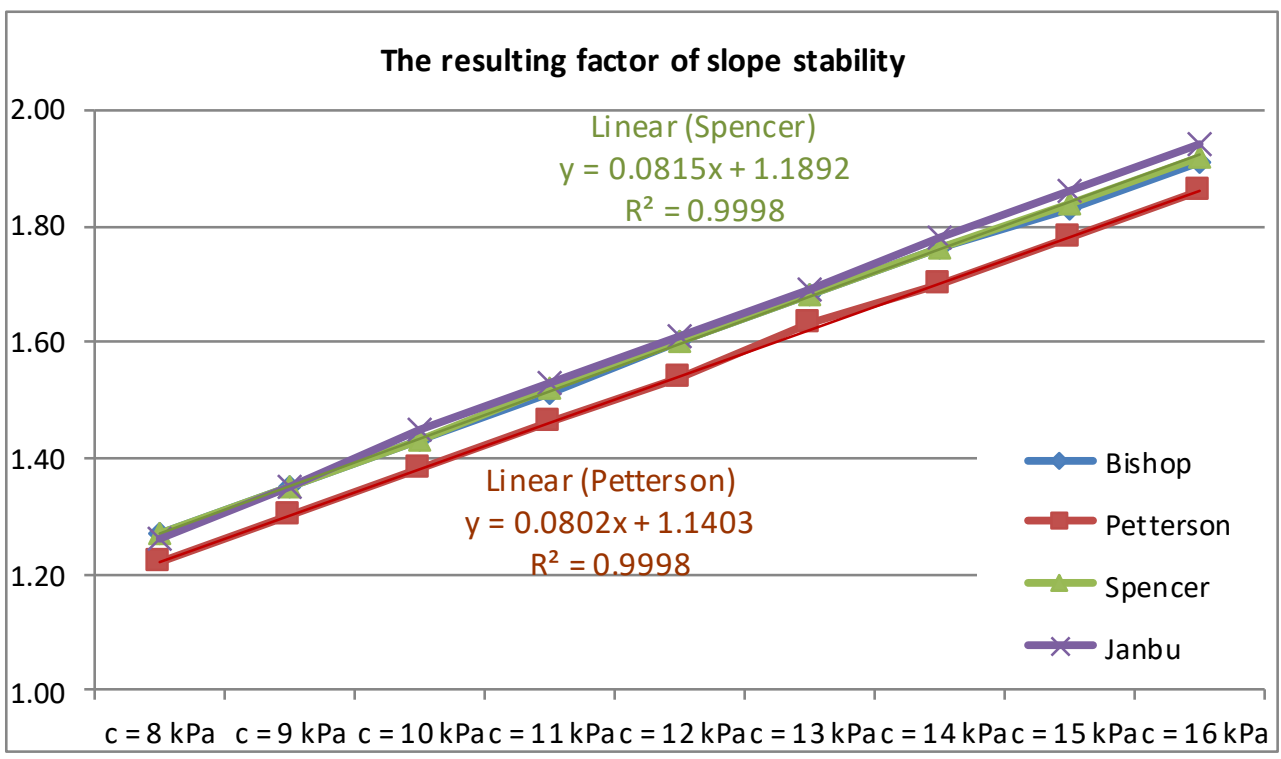

Fig. 4. The resulting factor of safety for $\varphi=17^{\circ}$ and $\mathrm{c}=(8-16) \mathrm{kPa}$. 
In this numerical analysis, the slope height is $H=4 \mathrm{~m}$, inclination of slope is $1: 1.25$, cohesion $c=(8-16) \mathrm{kPa}$ and angle of frictional $\varphi=(17-21)^{\circ}$ were used. Slope were considered as homogenous with $\gamma=21 \mathrm{~kg} . \mathrm{m}^{-3}$.

It has been found:

- When the cohesion of soil is changing and angle of internal friction is constant, the factor of safety has increased by about 0.6 to 0.7 (Fig. 4).

- The change in soil angle of friction for the constant value of the cohesion (Fig. 3) causes a slower increase in the factor of safety, only about 0.15 .

- The analysis for factor of safety shown in Figure 3 indicates strong linear relationship between the change in cohesion and the value of factor of safety - the correlation coefficient is $\mathrm{R}=0.9969$.

- The same effect is shown in Figure 4. Fig. 4 indicates strong linear relationship between the change in angle of friction and the value of factor of safety, the correlation coefficient is $\mathrm{R}=0.9998$.

- Changing in cohesion has a stronger effect on factor of safety than soil angle of friction.

- In all cases a factor of safety has the value over 1.0 indicates that the slope is considered stable.

- The lowest values of the factor of stability were calculated by the Petterson Method. It is the simplest method of slices not considering the action of neighbouring elements.

\section{Conclusion}

The first and foremost requirement for the analysis and design of slope is to guarantee their safety and reliability during their service life.

The experimental results represented by factor of safety of soil in terms of the change mechanical properties of the soil. To investigate effect of soil strength parameters on the factor of safety, different values of shear strength parameters: cohesion (c), internal friction angle $(\phi)$, were chosen. The influence the shear strength parameters of soil on the slope stability are very important, especially when changing the cohesion. After determining the correct values, the shear strength parameters, you can calculate correct value of the factor of safety of soil for the optimal design of slope without failure. Use incorrect shear parameters of soil, leading to local shear failure.

This work was supported by the Scientific Grant Agency of the Ministry of Education of Slovak Republic and the Slovak Academy of Sciences under Projects VEGA 1/0374/19.

\section{References}

1. S. K. Sarma, Géotechnique 23, 423-433, (1973)

2. STN-EN 1997-1. Eurocode 7. Geotechnical design, Part 1: General rules. (2005)

3. I. Ishibashi, H. Hazarika, Soil mechanics Fundamentals (CRC Press, Taylor \& Francis Group, 2010)

4. E. Panulinová, S. Harabinová. Advanced Material Research, Vol. 969, 245-248, (2014)

5. GEO 5 software $($ C Fine Ltd. 